\title{
Cytokeratin-positive cells in the bone marrow from patients with pancreatic, periampullary malignancy and benign pancreatic disease show no prognostic information
}

Harald Hugenschmidt ${ }^{1,2,3^{*}}$ (D), Knut Jørgen Labori ${ }^{3}$, Cathrine Brunborg ${ }^{4}$, Caroline Sophie Verbeke ${ }^{1,5}$, Lars Thomas Seeberg ${ }^{3,6}$, Cecilie Bendigtsen Schirmer ${ }^{5}$, Anne Renolen ${ }^{5}$, Elin Borgen ${ }^{5}$, Bjørn Naume ${ }^{1,7}$ and Gro Wiedswang ${ }^{3}$

\begin{abstract}
Background: Pancreatic and periampullary carcinoma are aggressive tumours where preoperative assessment is challenging. Disseminated tumour cells (DTC) in the bone marrow (BM) are associated with impaired prognosis in a variety of epithelial cancers. In a cohort of patients with presumed resectable pancreatic and periampullary carcinoma, we evaluated the frequency and the potential prognostic impact of the preoperative presence of DTC, defined as cytokeratin-positive cells detected by immunocytochemistry (ICC).

Methods: Preoperative BM samples from 242 patients selected for surgical resection of presumed resectable pancreatic and periampullary carcinoma from 09/2009 to 12/2014, were analysed for presence of CK-positive cells by ICC. The median observation time was 21.5 months. Overall survival (OS) and disease-free survival (DFS) were calculated by Kaplan-Meier and Cox regression analysis.

Results: Successful resections of malignant tumours were performed in 179 of the cases, 30 patients resected had benign pancreatic disease based on postoperative histology, and 33 were deemed inoperable intraoperatively due to advanced disease. Overall survival for patients with resected carcinoma was 21.1 months (95\% Cl: 18.0-24.1), for those with benign disease OS was 101 months (95\% Cl: 69.4-132) and for those with advanced disease OS was 8.8 months (95\% Cl: 4.3-13.3). The proportion of patients with detected CK-positive cells was 6/168 (3.6\%) in resected malignant cases, 2/31 (6.5\%) in advanced disease and 4/29 (13.8\%) in benign disease. The presence of CK-positive cells was not correlated to OS or DFS, neither in the entire cohort nor in the subgroup negative for circulating tumour cells (CTC).

(Continued on next page)
\end{abstract}

\footnotetext{
* Correspondence: harald@hugenschmidt.net

'Institute of Clinical Medicine, University of Oslo, Oslo, Norway

${ }^{2}$ Department of Transplantation Surgery, Oslo University Hospital, PO.Box

4950, NO-0424 Oslo, Nydalen, Norway

Full list of author information is available at the end of the article
}

(c) The Author(s). 2020 Open Access This article is licensed under a Creative Commons Attribution 4.0 International License, which permits use, sharing, adaptation, distribution and reproduction in any medium or format, as long as you give appropriate credit to the original author(s) and the source, provide a link to the Creative Commons licence, and indicate if changes were made. The images or other third party material in this article are included in the article's Creative Commons licence, unless indicated otherwise in a credit line to the material. If material is not included in the article's Creative Commons licence and your intended use is not permitted by statutory regulation or exceeds the permitted use, you will need to obtain permission directly from the copyright holder. To view a copy of this licence, visit http://creativecommons.org/licenses/by/4.0/ The Creative Commons Public Domain Dedication waiver (http://creativecommons.org/publicdomain/zero/1.0/) applies to the data made available in this article, unless otherwise stated in a credit line to the data. 
(Continued from previous page)

Conclusions: The results indicate that CK-positive cells may be present in both patients with malignant and benign diseases of the pancreas. Detection of CK-positive cells was not associated with differences in prognosis for the entire cohort or any of the subgroups analysed.

Trial registration: clinicaltrials.gov (NCT01919151).

Keywords: DTC, Disseminated tumour cells, Bone marrow, Pancreatic cancer, Periampullary cancer

\section{Background}

According to their anatomical origin, the main carcinoma types of the periampullary region are pancreatic ductal adenocarcinoma (PDAC), distal bile duct cancer (DBDC), ampullary cancer (AMPUC), and duodenal cancer (DUODC). They constitute an entity of aggressive tumours, particularly PDAC and DBDC where $80 \%$ of the cases have either locally advanced or metastatic disease at the time of diagnosis $[1,2]$. These tumours are potentially curable when diagnosed at an early, localised stage [3]. Still, the results from state of the art "surgery first" strategy [4], with radical resection followed by adjuvant therapy, are dismal. The expected rate of relapse during the first year after surgical resection is $50 \%$ and 5 -year survival rates below $10 \%[1,3]$.

The $\mathrm{BM}$ is a known reservoir for dormant or slowly proliferating, disseminated tumour cells (DTCs) [5], being part of the metastatic cascade in malignancies of epithelial origin [6]. The best validated DTC-detection method for BM-samples is based on density centrifugation and immunocytochemical (ICC) identification of a panel of Cytokeratins (CK). The morphological evaluation and categorization of the cells follows internationally standardized criteria by the ISHAGE-group [7-9]. Beyond prognostic information, there is well established evidence for the clinical utility of DTC detection in the management of the early stages of both breast $[10,11]$ and prostate cancer [5, 12]. There are several reports on the impact of DTC in pancreatic cancer in general, indicating an association of DTC with reduced survival [1317]. However, for the potential application as a predictive tool for presumed resectable periampullary cancers, the clinical relevance of DTC is unclear. A recent metaanalysis exploring the significance of CTC and DTC in PDAC-patients [18] revealed a significant association between DTC and survival for the entire cohort containing a mix of resectable and advanced cancers. In the subgroup of resected cancers only, the same study did not disclose a significant association, even though another study [13] had reported an association between DTC and impaired survival previously.

The aim of the present study was to explore the frequency and the prognostic impact of preoperatively detected DTCs in a cohort of patients with presumed resectable pancreatic and other periampullary cancers.

\section{Methods}

Patients, study design and follow-up

Between September 2009 and December 2014, patients referred to Oslo University Hospital, Norway with potentially resectable pancreatic and periampullary malignancy were included in a standardised preoperative workup and evaluation in a multidisciplinary tumour board as detailed previously [19]. Clinical data were recorded prospectively in an Epi-Info 3.5.3 database (CDC; Atlanta, GA; USA). The follow up included clinical status, computed tomography (CT) of the chest and abdomen as well as CA19-9 assessment twice a year. The mortality was deducted from the Norwegian Cause of Death Registry, provided by the Norwegian Institute of Public Health. The same patient cohort was described previously [20], with the observation period further extended by 25 months to January, 31st 2019. The study was undertaken in accordance to the $\operatorname{STROBE}(2014)$ and REMARK(2012) criteria for analysis and reporting.

\section{Detection of CK-positive cells in the bone marrow}

BM samples were collected under anaesthesia just prior to surgery, five $\mathrm{ml} \mathrm{BM}$ from the anterior iliac crest bilaterally in syringes containing $200 \mathrm{IE}$ Heparin in $0.5 \mathrm{ml}$ $\mathrm{NaCl}$. Samples were processed within $24 \mathrm{~h}$ at the Micrometastasis Laboratory, Oslo University Hospital, Norway as previously described [21]. BM mononuclear cells were isolated by density centrifugation over a Ficoll-Hypaque gradient (Lymphoprep ${ }^{\circ}$ Abbott Rapid Diagnostics AS, Oslo Norway) and cytospin-slides were prepared with $0.5 \times 10^{6} \mathrm{BM}-\mathrm{MNC} / \mathrm{slide}$. For each sample 4 slides (i.e. $2 \times 10^{6}$ cells) were immunostained for CK-positive cells with a combination of the monoclonal mouse primary antibodies AE1 and AE3 (Prod.\# MAB 1612 \& 1611, Milipore), with a broad affinity for the acidic and basic cytokeratin types, namely CK $1-8,10,14-16$ and 19 . The APAAP method for detection used a rabbit antimouse secondary antibody (Dako, \#Z0259) and an alkaline phosphatase-mouse-anti-alkaline phosphatase tertiary antibody (Dako, \#D0651), followed by a colour reaction with New Fuchsin, staining positive cells red [22]. Nuclear counterstaining was performed with haematoxylin. The cytospins were screened for ICCpositive cells in an automated Ariol SL50 analyser (Leica biosystems). Detected elements were reviewed by a 
trained research engineer (CBS) and candidate cells were classified by a dedicated pathologist (EB). The cytomorphological evaluation of detected ICC-positive cells was performed in accordance to the ISHAGE consensus guidelines $[7,8]$. This protocol, originally validated for breast cancer samples, has become the de facto standard for DTC reporting, including pancreatic cancer studies [13]. Based on this classification, and according to earlier practice [23], the ICCpositive cells are divided into 4 categories: tumour cells (TC), hematopoietic (ie "false positive") cells $(\mathrm{HC}), \mathrm{QHC}$ (questionable/probable $\mathrm{HC}$ ) and uninterpretable cells (UIC). If cells classified as TC or UIC were detected, 4 additional cytospins were incubated with the non-reactive mouse monoclonal antibody MOPC21 (Prod\# M9269, Sigma Aldrich) of the same Ig isotype as AE1AE3, and detected by APAAP as above, constituting a negative control for the ICC reaction. Samples harbouring cells classified as TC in AE1/AE3 slides and not in the corresponding negative control slides were classified as "DTC-positive". Samples harbouring cells classified as TC in AE1/AE3 slides and in the corresponding negative control slides were interpreted as "not evaluable" (n.e.) and excluded from further analysis. Samples harbouring "UIC", "HC" or "QHC" were interpreted as "DTCnegative". Results were stored in a database at the Micrometastasis Laboratory, Dept. of Pathology, Oslo University Hospital and were not available to treating clinicians. Following closure of the observation period, the classification of ICC-positive cells was combined with the clinical data using a scripted tool upon import to SPSS.

\section{Characteristics of the patient cohort}

Patients were categorised into three distinct clinical groups, see also Fig. 1. Patients who underwent surgical resection did either have confirmed malignancy (resectable cancer) or a non-malignant condition (benign disease). The third group consisted of advanced cancer patients who underwent exploratory laparotomy but did not undergo resection, either due to locally advanced tumour growth or overt metastases (advanced cancer).

In addition to the presence of ICC-positive cells, the following clinical- and pathological parameters were recorded: age, gender, CA19-9, tumour size on CT-scan, AJCC/UICC-stage (7th ed.), pTNM-staging including resection margin, cancer origin, grade of histopathological differentiation, histological subtype (predominantly intestinal or pancreatobiliary), vascular and perineural infiltration. Continuous variables were dichotomized at the following thresholds: CA19-9 $\geq 200 \mathrm{kU} / \mathrm{L}$ and the size of the lesion on CT-scan $\geq 25 \mathrm{~mm}$ (for results, see Table 1).

\section{Statistics}

Data were analysed in IBM SPSS, V25 (IBM Cooperation Analytics, Armonk, NY, USA) and STATA 15 (Stata Corp LLC, College Station, Texas, USA). Graphs were prepared in PRISM 8 (GraphPad Software Inc., La Jolla, CA, USA). The primary endpoints of the study were overall survival (OS), defined as survival until death by any cause and disease-free survival (DFS), defined as survival until signs of local relapse or metastasis were detected. Survival analyses were carried out with the Kaplan-Meier method, using the Log-rank test for difference of curve pairs. The association between TC-status and survival was quantified by a hazard ratio (HR) with a 95\% confidence interval $(\mathrm{CI})$ using Cox regression analysis. Statistical significance was assumed for $p<0.05$.

\section{Results}

\section{Patient group characteristics}

Two hundred seventy-seven patients were assessed during the study period of whom 35 patients (12.6\%) did not meet the inclusion criteria. Tumour resection with curative intent was performed in $86.4 \%$ of the patients (209/ $242)$, while in $13.6 \%(33 / 242)$ resection was not performed due to intraoperative detection of advanced disease. In patients deemed unresectable intraoperatively, a biliary or intestinal bypass procedure was performed in 24 patients and 9 received an explorative laparotomy. Of the cases with advanced disease, the tumour origin was the pancreatic head in 30 cases, the duodenum in two cases and in one case the distal bile duct. Of the 209 cases where a successful resection was performed, malignant tumours were confirmed in $85.6 \%(179 / 209)$, while $14.4 \%(30 / 209)$ a benign pancreatic disease was found. Thus, for the whole cohort, resected malignancies account for 74.0\% (179/242), advanced disease $13.6 \%(33 / 242)$ and benign pancreatic disease for $12.4 \%$ (30/242). The 90-day mortality in operated patients was $2.1 \%(5 / 242)$, all due to rapid cancer progression because of advanced disease, in one case additionally complicated by an anastomotic failure. $84.6 \%$ (31/ 212) of all patients with malignant disease were alive at the date of last follow-up. Ten patients had died from other causes than cancer relapse. Further details on clinical features, distribution of procedures and histopathological diagnoses of the cohort are summarised in Table 1.

\section{Overall survival for patient groups}

The median observation time for the entire cohort was 21.5 months (range 1.5-110). Median overall survival (OS) was estimated to 101 months (95\% CI: 69.4-132) in patients with a benign lesion, 21.1 months (95\% CI: 18.0-24.1) in the resectable cancer group and 8.8 months (95\% CI: 4.3-13.3) in patients with advanced cancer. Differences in OS between the subgroups were statistically significant (see also Fig. 2). 
Table 1 Clinical characteristics of the cohort according to patient groups including ICC-positive cell type status in bone marrow

\begin{tabular}{llll}
\hline & Resected cancers $(\boldsymbol{n}=\mathbf{1 7 9})$ & Advanced cancers $(\boldsymbol{n}=\mathbf{3 3})$ & Benign $(\boldsymbol{n}=\mathbf{3 0})$ \\
\hline Age, median [years] & $69(34-88)$ & $63(46-83)$ & $69(45-82)$ \\
Sex, male & $92(51.4 \%)$ & $19(57.6 \%)$ & $21(70.0 \%)$ \\
ICC-positivity: $\geq 1$ ICC-positive cell / $2 \times 10^{6} \mathrm{MNC}$ & & \\
(ICC-status numbers may differ due to varying number of inconclusive ICC-results per category) & $2 / 31(6.5 \%)$ & $4 / 29(13.8 \%)$ \\
TC & $6 / 168(3.6 \%)$ & $0 / 31(0.0 \%)$ & $2 / 30(6.7 \%)$ \\
UIC & $10 / 174(5.7 \%)$ & $2 / 30(6.7 \%)$ & $3 / 29(10.3 \%)$ \\
HC & $16 / 169(9.5 \%)$ & $3 / 28(7.9 \%)$ & $3 / 25(12.0 \%)$. \\
QHC & $12 / 135(8.8 \%)$ &
\end{tabular}

Preoperative Risk Factors

$\begin{array}{ll}\text { CA19-9 } \geq 200 \mathrm{kU} / \mathrm{l} & 51 / 127(40.2 \%) ; 52 \text { missing } \\ \text { Tumour size }>25 \mathrm{~mm} & 71(39.7 \%) \\ \text { Bilirubin }>50 \mu \mathrm{mol} / \mathrm{L} & 132 / 151(87.4 \%) ; 28 \text { missing }\end{array}$

Neoadjuvant

chemotherapy

Operation

PPPD

PD

Pancreatectomy

Venous resection

Adjuvant chemotherapy

Adjuant chemotherapy

Histopathologic results

Pancreatic cancer
Malignant IPMN
Distal bile duct ca.
Ampullary cancer
Duodenal cancer
Pancreatobiliary type
Intestinal type
Mucinous type

UICC-stage (V7): I

II
II
IV

N1-status

N

R1-status

Vascular infiltration

Perineural infiltration
GEMZ 6 (4.1\%)

FOLFIRINX $1(0.7 \%)$

$$
\begin{aligned}
& 146(82.6 \%) \\
& 25(14.0 \%) \\
& 8(4.5 \%)
\end{aligned}
$$

$49(27.4 \%)$

FLV: 91 (50.8\%)

GEMZ: 7 (3.9\%)

FLOX: $1(0.7 \%)$

none: $80(44.7 \%)$

17/28 (60.7\%); 5 missing

$20(60.6 \%)$

21/32 (65.6\%); 1 missing

GEMZ 1 (3.0\%)

BDB $24(72.7 \%)$

Exp.lap. 9 (27.3\%)

$29(96.7 \%)$

$1(3.3 \%)$

none

n.a.

Palliative chemotherapy31 (93.9\%)

$2(6.7 \%)$

n.a.

GEMZ Gemzitabine, FLV, FLOX, FOLFIRINOX Chemotherapy regimens; PD Pancreatico-duodenectomy, PPPD Pylorus preserving PD, BDB Biliodigestive bypass; Ex.lap. Explorative laparotomy; IPMN Intraductal pancreatic mucinous neoplasia; ben.tu. Benign tumour; AIP Autoimmune pancreatitis; chr. Panc. Chronic pancreatitis; inflam. Inflammation n.a. Not applicable; n.d. Not determined. Note: ICC-status numbers may differ due to varying number of inconclusive ICC-results per category 


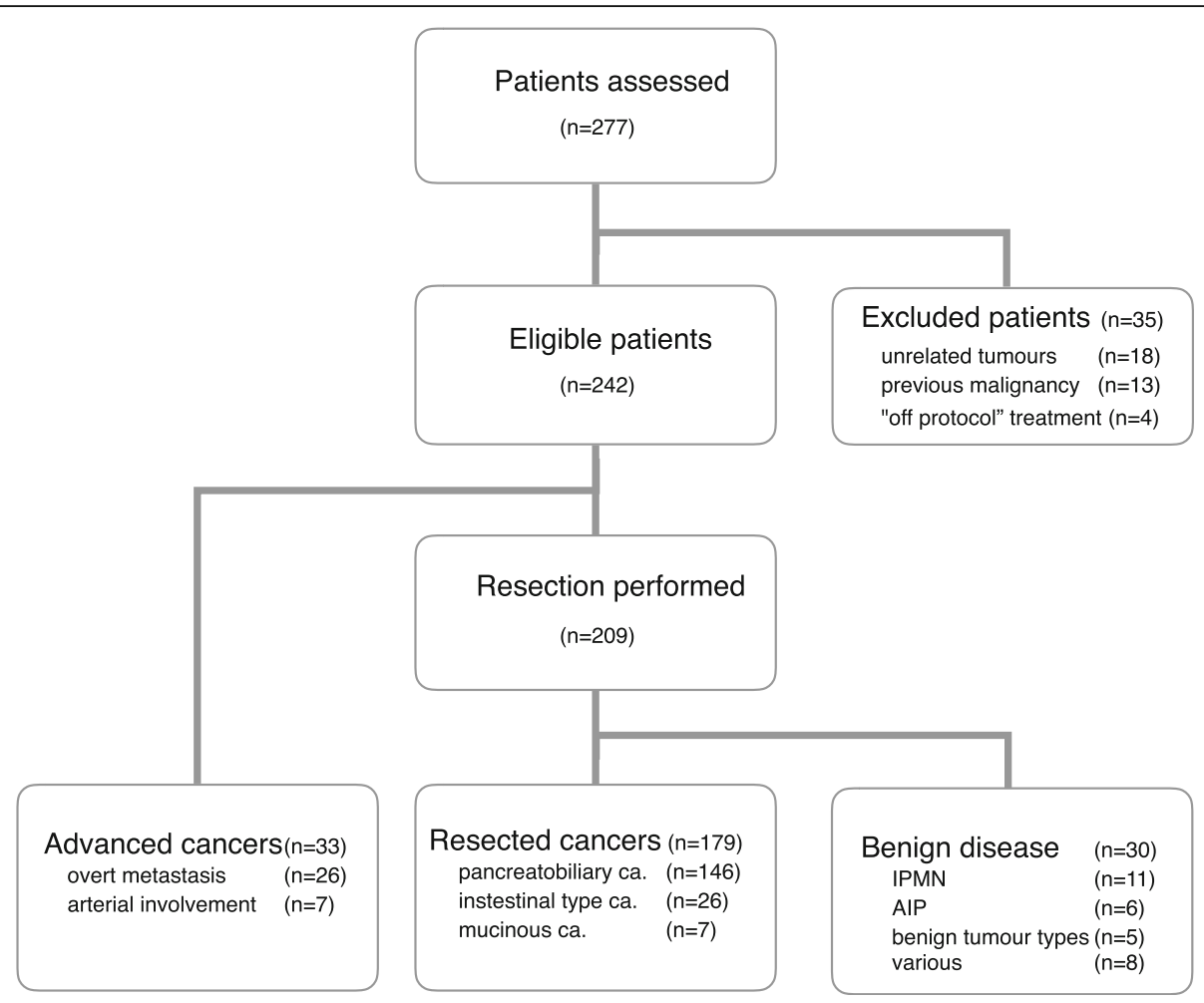

Fig. 1 Stratification of the patient cohort Legend: Study overview, showing group distribution, specifying causes for exclusion, histologic types, reasons for advanced cancer status and benign diagnoses. AIP: autoimmune pancreatitis; IPMN: intraductal mucinous neoplasia

Bone marrow ICC-positive cell types and patient survival ICC-positive cells of the named subtypes were identified both in patients with resected malignant tumours, in those with advanced cancers as well as in patients with benign pancreatic disease. According to patient group, DTCs were present in 6/168 (3.6\%) in resected cancers, $2 / 31(6.5 \%)$ in advanced cancers and $4 / 29(13.8 \%)$ in cases of benign pancreatic disease. The frequency of the other classes of ICCpositive cells in each prognostic group is presented in detail in Table 1. A per case specification of the distribution and frequency of all cell types together with the clinicopathological data are presented in Additional file 2. The low number of ICC-positive samples precludes subgroup analysis by tumour type. Survival analyses according to presence or absence of DTCs and the other ICC-positive cells are presented in Fig. 3 and Fig. 4, and in further detail in Table 2. DTC-positivity was associated with neither OS nor DFS. Furthermore, presence of other ICCpositive cells did not negatively impact on survival. The association between survival and presence of ICC-positive cells for benign disease was hampered by too few ICC-positive cases.
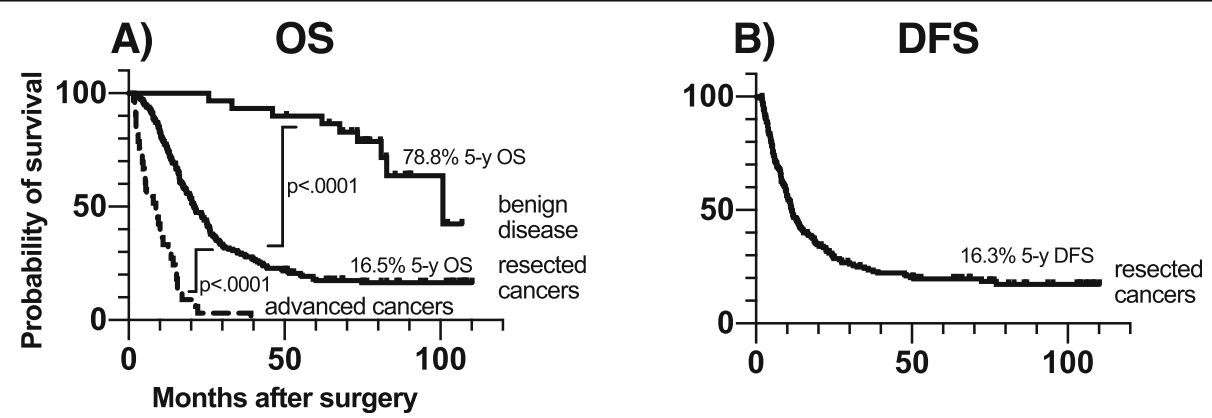

Fig. 2 Overall- and disease free survival for patient groups. Legend Kaplan-Meier curves, with 5-year survival and $P$ values (log Rank) for pairwise comparison between patient groups. A, Overall survival. B, Disease-free survival for resected patients. DFS: disease-free survival; OS: overall survival 


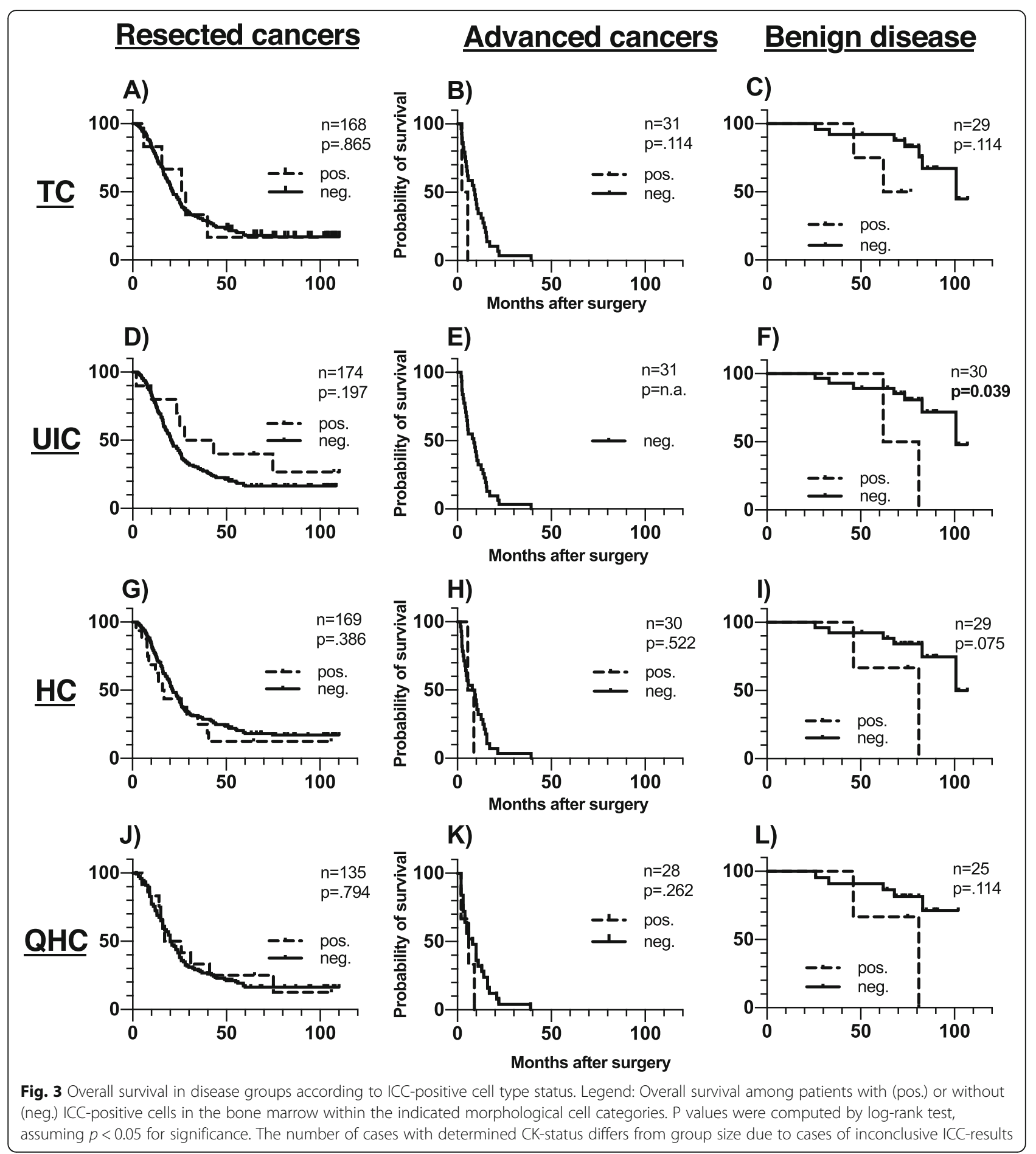

To account for the effect of CTC status and nodal status, as well as the weaker effects of vascular infiltration and histological type on survival of resected patients [20], we performed survival analyses subgrouped by these factors (Fig. 5). Patients with or without DTCs had similar outcome in those subgroups (Fig. 5). Presence other any other of the bone marrow ICC-positive cell types did not affect survival among the CTC-megative patients (Additional file 1). Among the CTC-positive patients, DTCs were not observed (Fig. 5) and in only one patient a single ICC-positive cell (HC) was detected (Additional file 1). 


\section{Resected cancers}

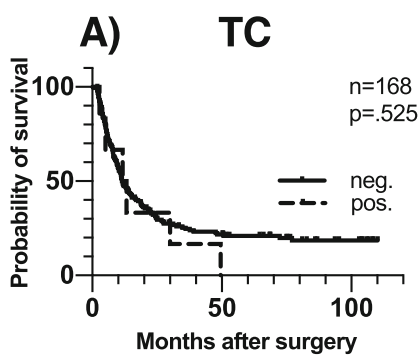

B) UIC
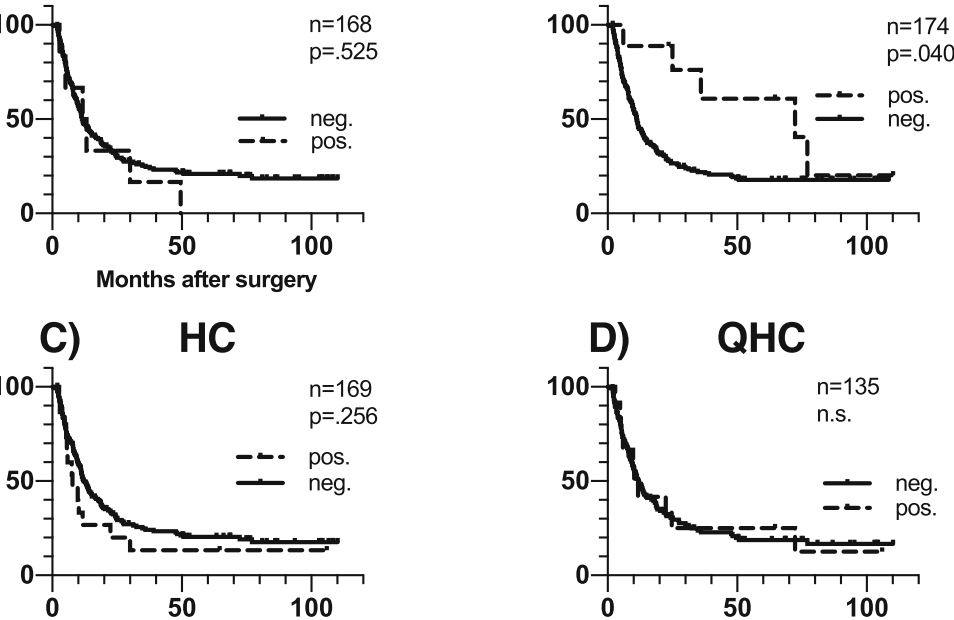

Fig. 4 Disease free survival among resected cancers according to ICC-positive cell type status. Legend: Disease free survival among patients with (pos.) or without (neg.) CK-positive cells in the BMwithin the indicated morphological cell categories. P values were computed by log-rank test, assuming $p<0.05$ for significance. The number of cases with determined CK-status differs from group size due to cases of inconclusive ICC-results

\section{Discussion}

\section{DTC frequency}

A low frequency of DTCs was detected in both resected (3.6\%) and advanced cancer patients (6.5\%). These numbers are less than half the frequencies reported from the largest patient series prior to the present study [13] which reported 13.5\% DTCpositivity for resected cancers and $13.9 \%$ for advanced cancers. Even higher positive rates of 38 to $57.1 \%$ were reported from earlier cohorts with smaller patient numbers and predominantly advanced stage cancers $[14,15,17]$. Complementary to the data from ICC-based studies, there were two studies using RT-PCR for CK-20 [24] detecting 33\% positive cases in a cohort of resectable PDAC [24] and CK-19 [25], detecting 67\% positives in a cohort of mixed stage cases [25] (see also Table 3). In the absence of comparative studies between ICC and PCR-based detection, the seemingly higher positive rates for PCR-based assays targeting a single CK category versus ICC utilising broad spectrum antibodies against a range of class I and class II CK-subtypes remains unexplained, although different sensitivity and/or specificity may contribute.

\section{Survival prediction}

Among resected pancreatic cancer patients, five ICCbased studies [13-17] reported a significant association between DTCs and impaired survival in univariate analysis (see also Table 3). In one of these studies [13], prognostic information was also retained in multivariate analysis (HR 2.755, $p=0.022$ ), while the four other studies did not test independent predictive value of DTC. There are two additional ICC-based studies on the same subject that did not discover an association between DTC status and survival [26, 27]. When weighing the evidence from these studies, several methodological differences have to be taken into consideration. The ISHAGE-group [7] established the first consensus on the cytomorphological criteria for the classification of ICC-positive cells in the BM for breast cancer patients. These criteria were later underscored in consensus reports [8,9] but also used in additional studies [23, 28].

Several of the studies mentioned above have been conducted prior to this standardisation or do not disclose their adherence to the ISHAGE criteria $[14,15$, 17]. Furthermore, there is a lack of standardisation concerning the choice of CK-detection antibodies, only one group [27] used the same antibody combination as in the present study. While not validated separately for gastrointestinal cancer types, the broad reactivity of the $\mathrm{AE} 1$ and $\mathrm{AE} 3$ antibody combinations which covers a spectrum of both the basic and acidic categories of CKs makes the assumption reasonable that the assay employed in the present study detects CK-positive cells independent from the tissue-type dependent differences in CK-subtype expression. The comparison of our results with the aforementioned studies may also be affected by the small size of 
Table 2 Overall survival according to ICC-positive cell type status in bone marrow

\begin{tabular}{|c|c|c|c|c|c|c|c|}
\hline ICC-type & Level & $\mathrm{N}$ & Incidentcases & Person months & $\mathrm{HR}(95 \% \mathrm{Cl})$ & $p$-value & Mean OS $(95 \% \mathrm{Cl})$ \\
\hline \multicolumn{8}{|c|}{ Overall survival, resected cancers } \\
\hline \multirow[t]{2}{*}{ TC } & Positive & 6 & 5 & 217.5 & $1.1(0.4-2.3)$ & 0.865 & $36.2(11.3-61.2)$ \\
\hline & Negative & 162 & 133 & 5293.6 & & & $37.1(31.6-42.6)$ \\
\hline \multirow[t]{2}{*}{ UIC } & Positive & 10 & 7 & 488.1 & $0.6(0.3-1.3)$ & 0.197 & $52.5(27.2-77.7)$ \\
\hline & Negative & 164 & 136 & 5144.0 & & & $35.6(30.2-40.9)$ \\
\hline \multirow[t]{2}{*}{$\mathrm{HC}$} & Positive & 16 & 14 & 431.6 & $1.3(0.7-2.2)$ & 0.386 & $29.6(14.3-44.8)$ \\
\hline & Negative & 153 & 125 & 5006.5 & & & $37.3(31.6-43.1)$ \\
\hline \multirow[t]{2}{*}{ QHC } & Positive & 12 & 10 & 419.0 & $0.9(.5-1.8)$ & 0.795 & $37.1(18.1-56.0)$ \\
\hline & Negative & 123 & 102 & 3817.1 & & & $35.5(29.2-41.8)$ \\
\hline \multicolumn{8}{|c|}{ Overall survival, advanced cancers } \\
\hline \multirow[t]{2}{*}{ TC } & Positive & 2 & 2 & 7.9 & $3.4(0.7-15.4)$ & 0.114 & $3.9(0.8-7.1) \mathrm{s}$ \\
\hline & Negative & 29 & 29 & 298.8 & & & $10.3(7.4-13.2)$ \\
\hline \multirow[t]{2}{*}{ UIC } & Positive & 0 & 0 & & - & - & \\
\hline & Negative & 31 & 31 & 306.6 & & & $9.9(7.1-12.7)$ \\
\hline \multirow[t]{2}{*}{$\mathrm{HC}$} & Positive & 2 & 2 & 14.3 & $1.6(0.4-7.2)$ & 0.522 & $7.2(4.0-10.3)$ \\
\hline & Negative & 28 & 28 & 266.6 & & & $9.5(6.5-12.5)$ \\
\hline \multirow[t]{2}{*}{$\mathrm{QHC}$} & Positive & 3 & 3 & 16.6 & $2.1(0.6-7.2)$ & 0.262 & $5.5(1.9-9.2)$ \\
\hline & Negative & 25 & 25 & 248.5 & & & $9.9(6.5-13.4)$ \\
\hline \multicolumn{8}{|c|}{ Overall survival, benign disease } \\
\hline \multirow[t]{2}{*}{ TC } & Positive & 4 & 2 & 256.1 & $4.0(0.7-22.6)$ & 0.114 & $65.3(53.0-77.6)$ \\
\hline & Negative & 25 & 7 & 1929.4 & & & $92.2(82.7-101.7)$ \\
\hline \multirow[t]{2}{*}{ UIC } & Positive & 2 & 2 & 143.0 & $5.7(1.1-25.5)$ & 0.039 & $71.5(52.9-90.1)$ \\
\hline & Negative & 28 & 7 & 1796.9 & & & $92.6(83.2-101.9)$ \\
\hline \multirow[t]{2}{*}{$\mathrm{HC}$} & Positive & 3 & 2 & 202.3 & $4.7(0.9-25.7)$ & 0.075 & $69.4(43.1-95.7)$ \\
\hline & Negative & 26 & 6 & 1867.3 & & & $93.7(84.3-103.2)$ \\
\hline \multirow[t]{2}{*}{ QHC } & Positive & 3 & 2 & 202.3 & $3.9(0.7-21.6)$ & 0.114 & $5.5(1.9-9.2)$ \\
\hline & Negative & 22 & 5 & 1639.1 & & & $9.9(6.5-13.4)$ \\
\hline \multicolumn{8}{|c|}{ Disease free survival, resected cancers } \\
\hline \multirow[t]{2}{*}{ TC } & Positive & 6 & 6 & 112.4 & $1.3(0.6-3.0)$ & 0.525 & $18.7(4.5-33.0)$ \\
\hline & Negative & 162 & 126 & 4022.2 & & & $32.2(25.9-38.5)$ \\
\hline \multirow[t]{2}{*}{ UIC } & Positive & 10 & 5 & 441.8 & $0.4(0.2-1.0)$ & 0.040 & $62.1(37.1-87.1)$ \\
\hline & Negative & 164 & 132 & 3785.8 & & & $29.4(23.5-35.4)$ \\
\hline \multirow[t]{2}{*}{$\mathrm{HC}$} & Positive & 16 & 16 & 299.4 & $1.4(0.8-2.5)$ & 0.277 & $22.6(5.7-39.5)$ \\
\hline & Negative & 153 & 120 & 3774.0 & & & $31.9(25.5-38.3)$ \\
\hline \multirow[t]{2}{*}{ QHC } & Positive & 12 & 10 & 340.7 & $1.0(0.5-1.9)$ & 0.973 & $30.1(10.1-50.8)$ \\
\hline & Negative & 123 & 96 & 2825.6 & & & $30.8(23.7-37.8)$ \\
\hline
\end{tabular}

Detailed survival analysis for patients with (pos.) or without (neg.) ICC-positive cells in the bone marrow in the indicated morphological cell categories. HR and $p$ values were computed by Cox-regression analysis. The number of patients analysed may differ from group size for cases with inconclusive ICC-results

several of the studies and mixed cohorts with predominantly advanced cancer stages [14-17]. Moreover, the substantial rate of surgical interventions performed outside established criteria for operability may have introduced a hidden stage migration [13]. Concerning the association of UIC-type cells with an inferior OS in patients with benign disease, there are only two UIC-positive cases out of 30 patients, rendering the result inconclusive. Although there seemed to be an association of UIC with an improved DFS for UIC-positive patients in the resected group, no difference in overall survival was observed. Since DFS and OS are tightly linked in these patients the clinical relevance of this finding is questionable. 


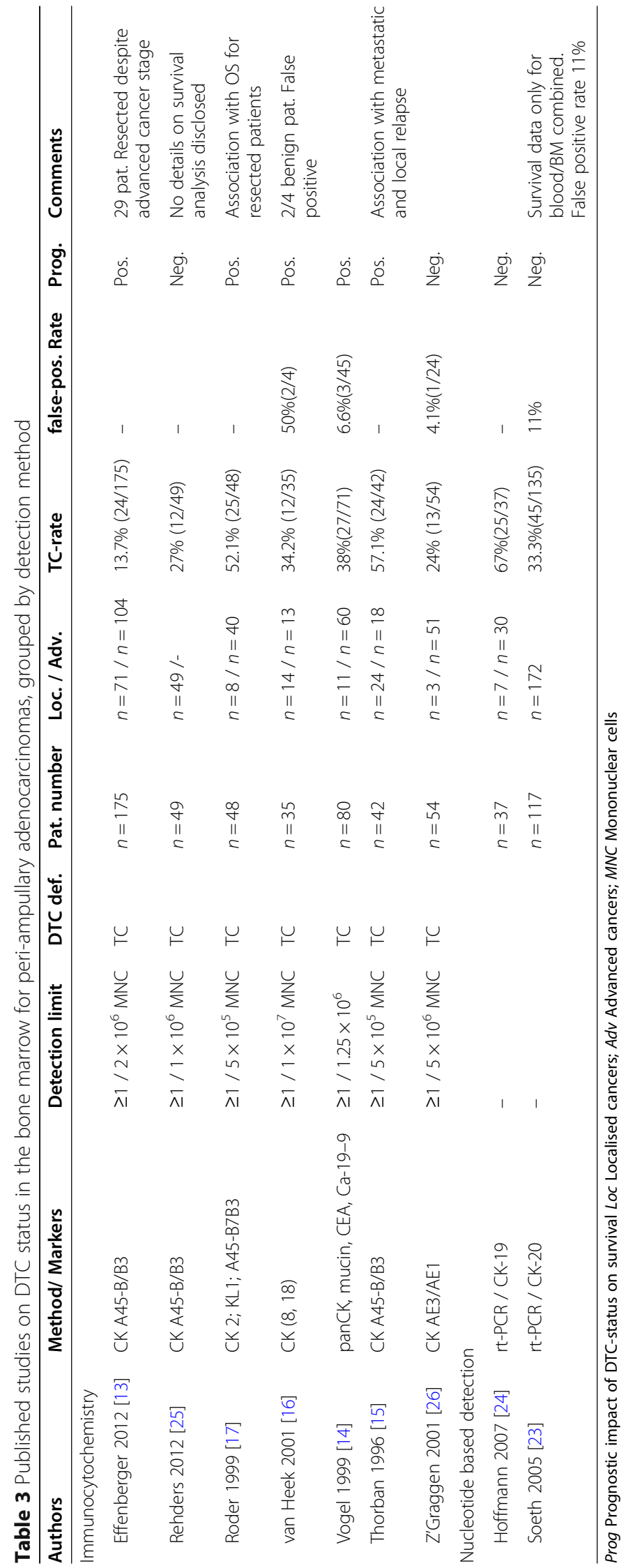




\section{Resected cancers}
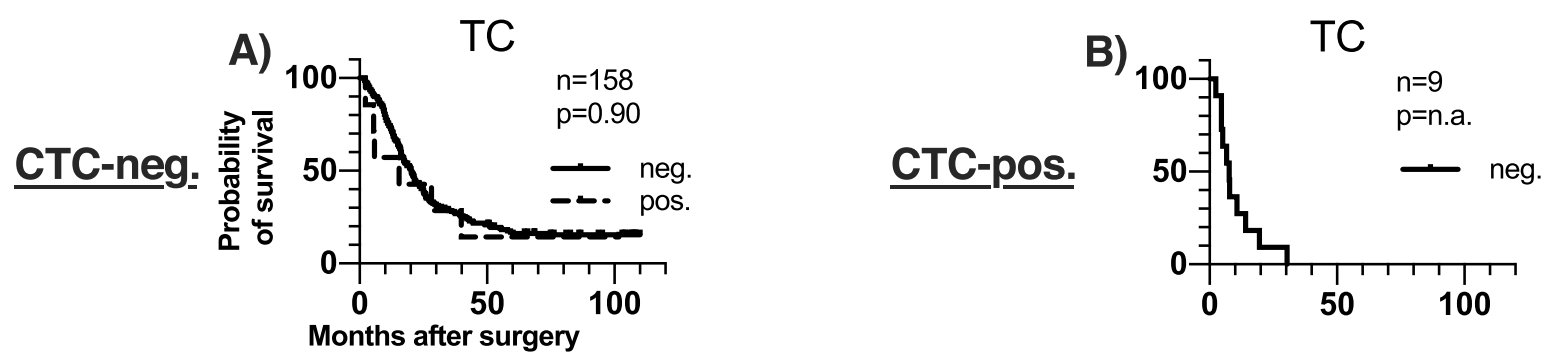

C)

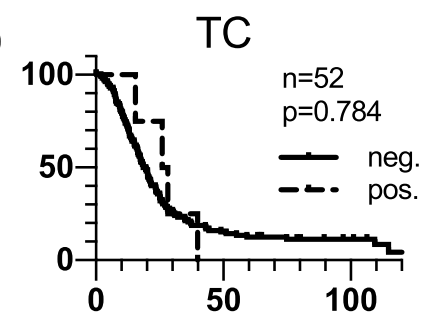

D)

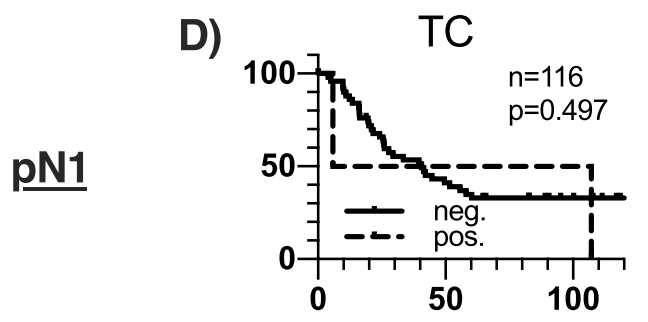

E)

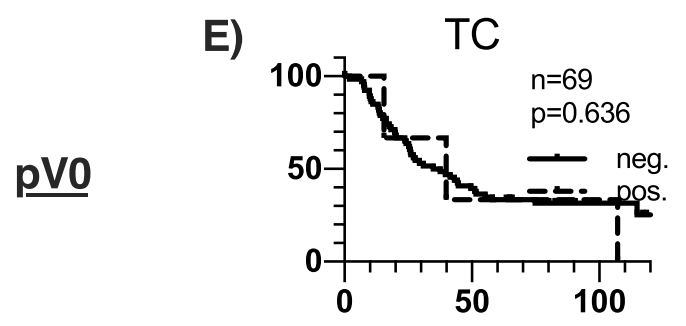

pN1

pVo
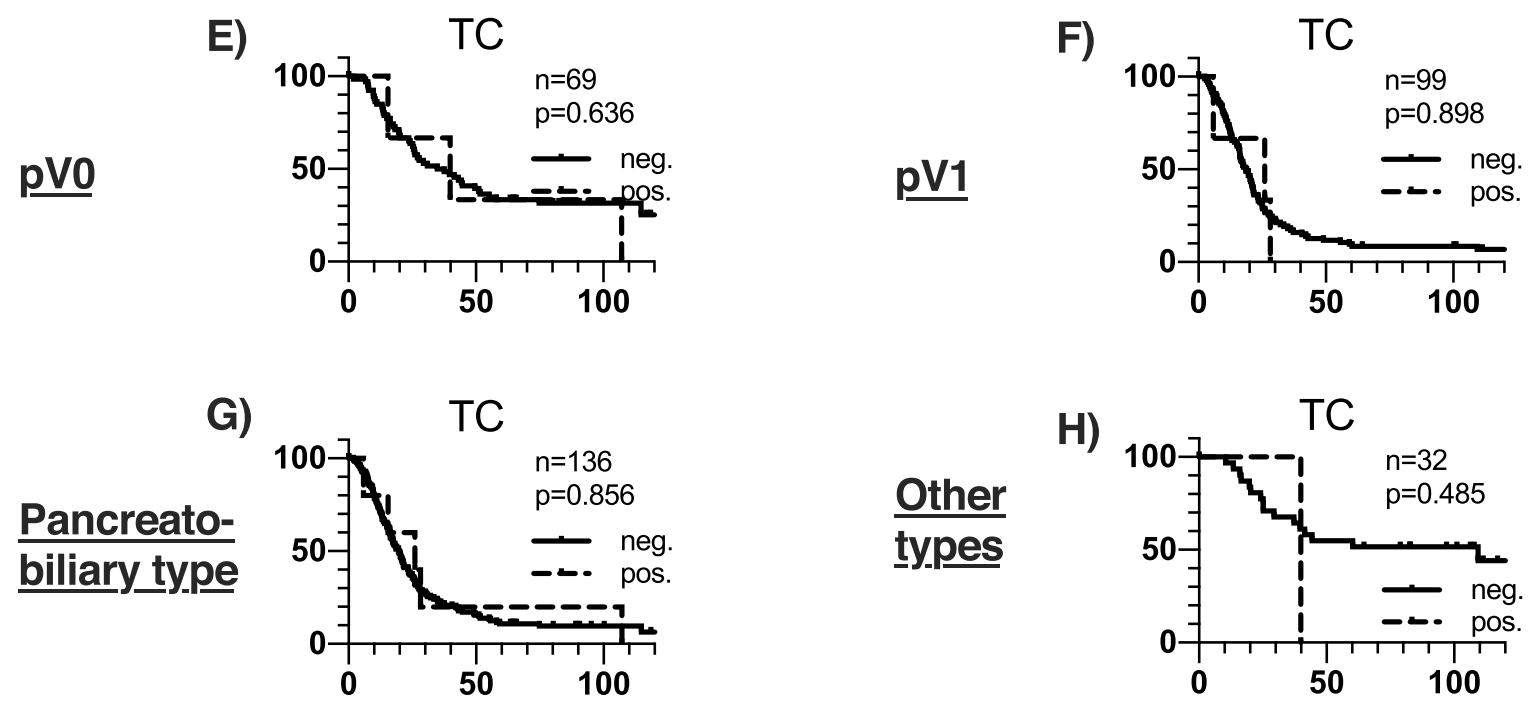

\section{Advanced cancers}
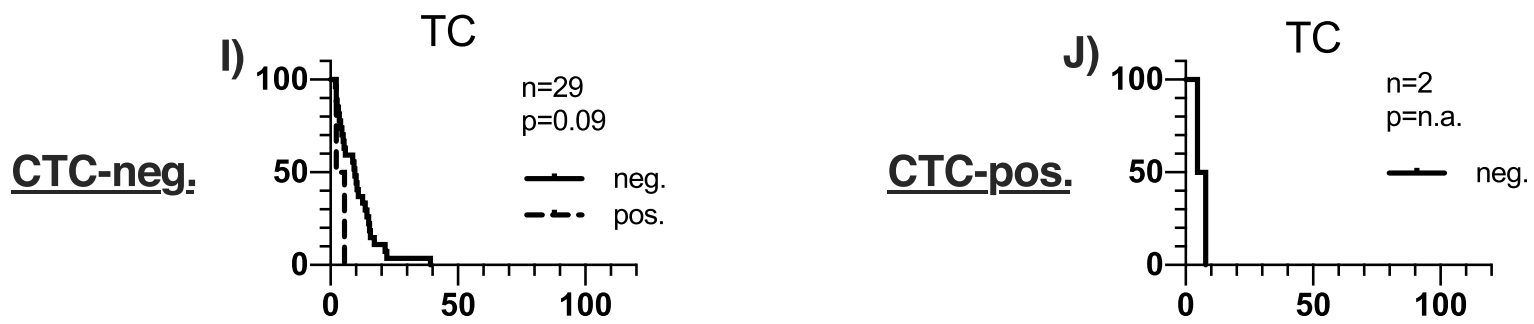

Fig. 5 (See legend on next page.) 
(See figure on previous page.)

Fig. 5 Cancer specific survival by prognostic subgroups in resected and advanced cancers according to TC-status. Legend: Overall survival dependent on CTC-status for resected and advanced cancer patients with (pos.) or without (neg.) TC cells. P values were computed by log-rank test, assuming $p<0.05$ for significance. The number of cases with determined CK-status differs from group size due to cases of inconclusive ICC-results

\section{ICC-positive cases in benign pancreatic disease}

In the present study, ICC-positive cells meeting the morphological criteria for DTC were detected in four out of 29 patients with benign pancreatic disease, for one more patient the analysis was inconclusive. The majority of ICC-based studies have excluded patients with benign pancreatic disease a priori from the analysis [13-15, 17, 26]. Therefore, previous evidence on the validity of the results from the present cohort is limited. This observed rate of $13 \%$ is far above the established rate of $2-3.5 \%$ for false positive events for the ICC-based assay [7, 15, 27, 29]. The presence of occult malignancy in those patients as the source for those cells is unlikely since none of the patients were diagnosed with cancer later during the observation period and none had a previous history of malignancy. While the nature of those cells cannot be further determined in the present study, there are independent reports on cells of seemingly epithelial origin in the $\mathrm{BM}$ and peripheral blood of PDACpatients. One ICC-based study reported results from four patients with benign disease, disclosing two ICCpositive cases [16]. In their conclusion the authors deem their method unfit for clinical use in PDAC due to the unreliability of the assay. Also one of the PCR-based studies report a rate of $11 \%$ in cases with benign pancreatic disease, while reporting only one positive case in 20 healthy controls [30]. In addition, there is one report disclosing the presence of epithelial cells in the bloodstream of patients with benign pancreatic disease [31]. These cells could potentially enter the BM via the bloodstream and could thereby be detected in BM-samples as well. Another possibility for the non-malignant origin of epithelial cells could be the shedding of epithelial cells from the pancreatic- and bile ducts or the duodenal wall during interventions, especially in the presence of inflammation [32]. Interestingly, all of the four ICC-positive cases in benign pancreatic disease in the present study had undergone invasive procedures preoperatively, either ERCP, endoscopic biopsy or bile duct stenting.

\section{Conclusions}

The results from our study of a large cohort of patients with presumed resectable periampullary cancer show a low frequency of CK-positive cases in both resectable cancer, advanced cancer group and non- malignant pancreatic disease. No association with CK-status and survival was observed. For the UIC cell type, an association with disease free-survival was observed, but this was not supported by overall survival data and the relevance of the association is questionable. Cells satisfying predefined consensus criteria for DTC/CK-positive cells in the BM were detected both in patients with malignant as well as benign pancreatic disease. The combination of low frequency of CK-positive cells and their presence in benign pancreatic disease cases indicates that the ICC-based CK-detection method used in the present study does not reliably identify relevant cells of malignant origin for the type of cancers studied. Nevertheless, additional studies including further characterisation of the cells, preferably with single cell techniques are encouraged.

\section{Supplementary information}

Supplementary information accompanies this paper at https://doi.org/10. 1186/s12885-020-07510-z.

Additional file 1 Figure S1: Overall survival sub-grouped by CTC status in resected and advanced cancers according to non-malignant ICC-status in bone marrow. Legend: Overall survival dependent on CTC-status for resected and advanced cancer patients with (pos.) or without (neg.) ICCpositive cells. $P$ values were computed by log-rank test assuming $P<0.05$ for significance. The number of cases with determined CK-status differs from group size due to cases of inconclusive ICC-results.

Additional file $\mathbf{2}$ Table S1: Clinical parameters of all ICC-positive patients

\section{Abbreviations}

AJCC/UICC: American joint committee on cancer / union internationale contre le cancere; AMPUC: Ampullary cancer; APAAP: Alkaline phosphataseanti-alkaline phosphatase; BM: Bone marrow; CDC: Centre for disease control; $\mathrm{Cl}$ : Confidence interval; CK: Cytokeratin; CT: Computed tomography x-ray; CTC: Circulating tumour cells; DBDC: Distal bile duct cancer; DFS: Disease-free survival; DTC: Disseminated tumour cells; DUODC: Duodenal cancer; HC: Hematopoietic cells; ICC: Immuno-cytochemistry; ISHAGE: International society of hematotherapy and graft engineering; MNC: Mononuclear cells; OS: Overall survival; PDAC: Pancreatic ductal adenocarcinoma; pTNM: Pathological tumour stage, nodal status, metastastis status; QHC: Questionable/probable hematopoietic cells; REMARK: Reporting recommendations for tumour marker prognostic studies;

STROBE: Strengthening the reporting of observational studies in epidemiology; TC: Tumour cells; UIC: Uninterpretable cells

Acknowledgements

Not applicable

Authors' contributions

The concept of the present study was developed by GW, HH, KJL and BN. The acquisition of clinical data was performed by KJL, HH, LTS, the histopathological data by CSV. CTC analyses and the interpretation of results were performed by CBS, AR and EB. Statistical analyses were performed by 
CB. All authors were involved in the interpretation of the data with full access to the primary data and have approved the submitted version. The authors have agreed to be personally accountable for their own contributions and to ensure that questions related to the integrity and accuracy of any part of the present work are appropriately investigated, resolved and the resolution documented in the literature.

\section{Funding}

This work was supported by a research grant from Helse Sør-Øst (Regional health-authority) to GW that covered the costs of laboratory analyses for the present study. $\mathrm{HH}$ had a part-time junior researcher position funded by Helse Sør-Øst over four years in the beginning of the study period. The funding entity was neither involved in the design of the present study nor were results disclosed previous to publication.

\section{Availability of data and materials}

The datasets used and/or analysed during the current study are available from the corresponding author on reasonable request.

\section{Ethics approval and consent to participate}

All patients selected for surgery were offered participation in this prospective, observational study and asked for their written informed consent. Exclusion criteria were a history of other malignancies in the past 10 years, failure to adhere to standard treatment and infrequent cancer types such as neuroendocrine carcinoma. The study protocol was approved by the Regional Ethical Committee (Helse Sør-Øst; Ref. 93-08172d 6.2008.540) in Oslo, Norway and registered at clinicaltrials.gov (NCT01919151). Clinical data were recorded prospectively in a database that was approved by and maintained as regulated by the Oslo University Hospital guidelines, supervised by the Data Protection Officer for Research.

\section{Consent for publication}

Not applicable.

\section{Competing interests}

None of the authors has any conflicting interest to disclose.

\section{Author details}

${ }^{1}$ Institute of Clinical Medicine, University of Oslo, Oslo, Norway. ${ }^{2}$ Department of Transplantation Surgery, Oslo University Hospital, PO.Box 4950, NO-0424 Oslo, Nydalen, Norway. ${ }^{3}$ Department of Gastrointestinal Surgery, Oslo University Hospital, Oslo, Norway. ${ }^{4}$ Oslo Centre for Biostatistics and Epidemiology, Oslo University Hospital, Oslo, Norway. ${ }^{5}$ Department of Pathology, Oslo University Hospital, Oslo, Norway. ${ }^{6}$ Department of Gastrointestinal Surgery, Vestfold Hospital Trust, Tønsberg, Norway. ${ }^{7}$ Deparment of Oncology, Oslo University Hospital, Oslo, Norway.

\section{Received: 26 November 2019 Accepted: 7 October 2020}

\section{Published online: 16 November 2020}

\section{References}

1. Søreide K, Aagnes B, Møller B, Westgaard A, Bray F. Epidemiology of pancreatic cancer in Norway: trends in incidence, basis of diagnosis and survival 1965-2007. Scand J Gastroenterol. 2010;45(1):82-92.

2. Li D, Xie K, Wolff R, Abbruzzese JL. Pancreatic cancer. Lancet. 2004; 363(9414):1049-57.

3. He J, Ahuja N, Makary MA, Cameron JL, Eckhauser FE, Choti MA, et al. 2564 resected periampullary adenocarcinomas at a single institution: trends over three decades. HPB (Oxford). 2014;16(1):83-90.

4. Tempero MA, Malafa MP, Al-Hawary M, Asbun H, Bain A, Behrman SW, et al. Pancreatic adenocarcinoma, version 2.2017, NCCN clinical practice guidelines in oncology. J Natl Compr Canc Netw. 2017;15(8):1028-61.

5. Morrissey C, Vessella RL, Lange PH, Lam H-M. The biology and clinical implications of prostate cancer dormancy and metastasis. J Mol Med. 2016; 94(3):259-65.

6. Pantel K, Alix-Panabières C, Riethdorf S. Cancer Micrometastases. Nat Rev Clin Oncol 2009;6(6):339-51. https://doi.org/10.1038/nrclinonc.2009.44.

7. Borgen E, Naume B, Nesland JM, Kvalheim G, Beiske K, Fodstad O, et al. Standardization of the immunocytochemical detection of cancer cells in BM and blood: I. establishment of objective criteria for the evaluation of immunostained cells. Cytotherapy. 1999;1(5):377-88.
8. Fehm T, Braun S, Müller V, Janni W, Gebauer G, Marth C, et al. A concept for the standardized detection of disseminated tumor cells in bone marrow from patients with primary breast cancer and its clinical implementation. Cancer. 2006;107(5):885-92.

9. Borgen E, Pantel K, Schlimok G, Müller P, Otte M, Renolen A, et al. A European interlaboratory testing of three well-known procedures for immunocytochemical detection of epithelial cells in bone marrow. Results from analysis of normal bone marrow. Cytometry B Clin Cytom. 2006;70(6): 400-9.

10. Mignot F, Loirat D, Dureau S, Bataillon G, Caly M, Vincent-Salomon A, et al. Disseminated tumor cells predict efficacy of regional nodal irradiation in early stage breast cancer. Int J Radiat Oncol Biol Phys. 2018;3:389-96.

11. Naume B, Synnestvedt M, Falk RS, Wiedswang G, Weyde K, Risberg T, et al. Clinical outcome with correlation to disseminated tumor cell (DTC) status after DTC-guided secondary adjuvant treatment with docetaxel in early breast cancer. J Clin Oncol. 2014;32(34):3848-57.

12. Todenhöfer T, Hennenlotter J, Faber F, Wallwiener D, Schilling D, Kühs U, et al. Significance of apoptotic and non-apoptotic disseminated tumor cells in the bone marrow of patients with clinically localized prostate cancer. Prostate. 2015;75(6):637-45.

13. Effenberger KE, Schroeder C, Eulenburg C, Reeh M, Tachezy M, Riethdorf S, et al. Disseminated tumor cells in pancreatic cancer-an independent prognosticator of disease progression and survival. Int J Cancer. 2012;131(4): E475-83.

14. Vogel I, Krüger U, Marxsen J, Soeth E, Kalthoff H, Henne-Bruns D, et al. Disseminated tumor cells in pancreatic cancer patients detected by immunocytology: a new prognostic factor. Clin Cancer Res. 1999;5(3):593-9.

15. Thorban S, Roder JD, Pantel K, Siewert JR. Epithelial tumour cells in bone marrow of patients with pancreatic carcinoma detected by immunocytochemical staining. Eur J Cancer. 1996;32(2):363-5.

16. van Heek NT, Tascilar M, van Beekveld JL, Drillenburg P, Offerhaus GJA, Gouma DJ. Micrometastases in bone marrow of patients with suspected pancreatic and ampullary cancer. Eur J Surg Oncol. 2001;27(8):740-5.

17. Roder JD, Thorban S, Pantel K, Siewert JR. Micrometastases in bone marrow: prognostic indicators for pancreatic cancer. World J Surg. 1999;23(9):888-91.

18. Stephenson D, Nahm C, Chua T, Gill A, Mittal A, de Reuver P, et al. Circulating and disseminated tumor cells in pancreatic cancer and their role in patient prognosis: a systematic review and meta-analysis. Oncotarget Impact Journals. 2017;8(63):107223-36.

19. Labori KJ, Katz MH, Tzeng CW, Bjørnbeth BA, Cvancarova M, Edwin B, et al. Impact of early disease progression and surgical complications on adjuvant chemotherapy completion rates and survival in patients undergoing the surgery first approach for resectable pancreatic ductal adenocarcinoma - a population-based cohort study. Acta Oncol. 2016;55(3):265-77.

20. Hugenschmidt H, Labori K, Brunborg C, Verbeke CS, Seeberg LT, Schirmer $\mathrm{CB}$, et al. Circulating tumor cells are an independent predictor of shorter survival in patients undergoing resection for pancreatic and Periampullary adenocarcinoma. Ann Surg. 2020;271(3):549-58.

21. Wiedswang G, Borgen E, Kåresen R, Kvalheim G, Nesland JM, Qvist H, et al, Detection of isolated tumor cells in bone marrow is an independent prognostic factor in breast cancer. J Clin Oncol. 2003;21(18):3469-78.

22. Cordell JL, Falini B, Erber WN, Ghosh AK, Abdulaziz Z, MacDonald S, et al. Immunoenzymatic labeling of monoclonal antibodies using immune complexes of alkaline phosphatase and monoclonal anti-alkaline phosphatase (APAAP complexes). J Histochem Cytochem. 1984;32(2):21929.

23. Synnestvedt M, Borgen E, Schlichting E, Schirmer CB, Renolen A, Giercksky $\mathrm{KE}$, et al. Disseminated tumour cells in the bone marrow in early breast cancer: morphological categories of immunocytochemically positive cells have different impact on clinical outcome. Breast Cancer Res Treat. 2013; 138(2):485-97.

24. Soeth E, Grigoleit U, Moellmann B, Röder C, Schniewind B, Kremer B, et al. Detection of tumor cell dissemination in pancreatic ductal carcinoma patients by CK 20 RT-PCR indicates poor survival. J Cancer Res Clin Oncol. 2005;131(10):669-76

25. Hoffmann K, Kerner C, Wilfert W, Mueller M, Thiery J, Hauss J, et al. Detection of disseminated pancreatic cells by amplification of cytokeratin19 with quantitative RT-PCR in blood, bone marrow and peritoneal lavage of pancreatic carcinoma patients. World J Gastroenterol. 2007;13(2):257-63.

26. Rehders A, Stoecklein NH, Güray A, Riediger R, Alexander A, Knoefel WT. Vascular invasion in pancreatic cancer: tumor biology or tumor topography? 
Surgery. 2012;152(3 Suppl 1):S143-51 Available from: http://eutils.ncbi.nlm. nih.gov/entrez/eutils/elink.fcgi?dbfrom=pubmed\&id=22766363\&retmode= ref\&cmd=prlinks.

27. Z'graggen K, Centeno BA, Fernandez-del Castillo C, Jimenez RE, Werner J, Warshaw AL. Biological implications of tumor cells in blood and bone marrow of pancreatic cancer patients. Surgery. 2001;129(5):537-46.

28. Bidard F-C, Vincent-Salomon A, Gomme S, Nos C, de Rycke Y, Thiery JP, et al. Disseminated tumor cells of breast cancer patients: a strong prognostic factor for distant and local relapse. Clin Cancer Res. 2008;14(11): 3306-11.

29. Schlimok G, Funke I, Holzmann B, Göttlinger G, Schmidt G, Häuser H, et al. Micrometastatic cancer cells in bone marrow: in vitro detection with anticytokeratin and in vivo labeling with anti-17-1A monoclonal antibodies. Proc Natl Acad Sci USA. 1987;84(23):8672-6.

30. Soeth E, Vogel I, Röder C, Juhl H, Marxsen J, Krüger U, et al. Comparative analysis of bone marrow and venous blood isolates from gastrointestinal cancer patients for the detection of disseminated tumor cells using reverse transcription PCR. Cancer Res. 1997;57(15):3106-10.

31. Rosenbaum MW, Cauley CE, Kulemann B, Liss AS, Castillo CF-D, Warshaw AL, et al. Cytologic characteristics of circulating epithelioid cells in pancreatic disease. Cancer. 2017;125(5):332-40.

32. Liu JJ, Wong K, Thiesen AL, Mah SJ, Dieleman LA, Claggett B, et al. Increased epithelial gaps in the small intestines of patients with inflammatory bowel disease: density matters. Gastrointest Endosc. 2011;73(6):1174-80.

\section{Publisher's Note}

Springer Nature remains neutral with regard to jurisdictional claims in published maps and institutional affiliations.

Ready to submit your research? Choose BMC and benefit from:

- fast, convenient online submission

- thorough peer review by experienced researchers in your field

- rapid publication on acceptance

- support for research data, including large and complex data types

- gold Open Access which fosters wider collaboration and increased citations

- maximum visibility for your research: over $100 \mathrm{M}$ website views per year

At $\mathrm{BMC}$, research is always in progress.

Learn more biomedcentral.com/submissions 